\title{
Suppression of fetal gonadotrophin concentrations by maternal passive immunization to $\mathrm{GnRH}$ in sheep
}

\author{
D. W. Miller* , H. M. Fraser and A. N. Brooks ${ }^{\dagger}$ \\ MRC Reproductive Biology Unit, Centre for Reproductive Biology, 37 Chalmers Street, \\ Edinburgh EH3 $9 E W$, UK
}

\begin{abstract}
The hypothalamo-pituitary-gonadal axis matures during fetal life and may be susceptible to adverse effects. Model systems can be used to understand its physiological role. The aim of this study was to determine whether antibodies to $\mathrm{GnRH}$, administered to the mother, can cross the ovine fetal-placental barrier and suppress fetal gonadotrophin secretion. Maternal passive immunization to $\mathrm{GnRH}$ in pregnant Greyface ewes (day 103 of gestation) resulted in $\mathrm{GnRH}$ antibody titres of from 1:6000 to 1:9000 after 1 day and a suppression of the pulsatile secretion of fetal LH after 2 days. Fetal FSH concentrations declined gradually over the 11 days of the experiment and were only significantly different from control animals immunized against BSA in male fetuses. The slower decrease in fetal FSH concentrations than in LH concentrations shows that the secretion of FSH, unlike that of LH, is not dependent on short term changes in GnRH release. The lack of a suppressive effect of the maternal GnRH immunoneutralization on female fetal FSH secretion may be due to removal of the negative feedback effect of oestradiol and, possibly, inhibin. There was no sexual dimorphism in the effect of maternal GnRH immunoneutralization on fetal GnRH antibody titres or fetal LH secretion. These findings show that maternal passive immunization against $\mathrm{GnRH}$ results in $\mathrm{GnRH}$ antibodies crossing the fetal-placental barrier and suppressing fetal $\mathrm{LH}$ and FSH secretion in males, but only suppressing LH secretion in the females. Although the lack of effect on FSH secretion in the females needs to be investigated further, the present study provides evidence of a non-invasive procedure for blocking fetal gonadotrophin secretion which may be used to investigate hypothalamo-pituitary-gonadal function during early gestation in sheep.
\end{abstract}

\section{Introduction}

A number of disorders of reproduction in humans, including a reported decline in sperm counts, may be the consequence of alteration of gonadotrophin concentrations in the fetus (Jensen et al., 1995). Sheep models that have been used to examine the fetal pituitary-gonadal axis have shown that inhibition of fetal gonadotrophin secretion, by use of subcutaneous implants of a $\mathrm{GnRH}$ agonist, can lead to reduced testicular size and fewer Sertoli cells at birth (Thomas et al., 1994). However, the surgical method of implantation is potentially stressful on the fetus and can be carried out only after mid-gestation when circulating gonadotrophin concentrations are at their highest (Brooks and Thomas, 1995). A method of inhibiting gonadotrophin secretion earlier in gestation is required to investigate mechanisms of reproductive development.

*Present address: Department of Agriculture, University of Aberdeen, 581 King St, Aberdeen AB24 5UA, UK.

${ }^{\dagger}$ Present address: Zeneca Central Toxicology Laboratory, Alderley Park, Macclesfield, Cheshire SK10 4TJ, UK.

Received 30 June 1997.
Immunoneutralization of GnRH by injection of antiserum raised against the decapeptide in aduit ewes and rams results in an immediate blockade of pulsatile LH secretion (Lincoln and Fraser, 1979; Fraser and McNeilly, 1983). Therefore, maternal passive immunization to $\mathrm{GnRH}$ may provide a non-invasive procedure for immunizing the fetus against $\mathrm{GnRH}$ and, hence, allow examination of how and when inhibition of fetal gonadotrophin secretion affects the normal ontogeny of the pituitary-gonadal axis. However, this system would rely on the $\mathrm{GnRH}$ antibodies crossing the fetal-placental barrier and being bioactive to suppress both LH and FSH.

The anatomy of the fetal-maternal interface, with complete separation of fetal and maternal circulation, provides protective advantages to the conceptus. Exchange of various components is enabled by the trophoblast which acts as a filter limiting the transfer of cells and antibodies from the mother to the fetus. Certain antibodies do gain access across the fetal-placental barrier. In particular, IgG antibodies have been shown to cross the placenta in humans, pigs and mice (Isreal et al., 1995; Jauniaux et al., 1995; Tuo et al., 1996) and there is some evidence that IgG antibodies cross the fetal-placental barrier in sheep (Sanderson et al., 1994). Therefore, an antibody to GnRH 
may be able to gain access to the fetal circulation from the maternal circulation, and subsequently suppress gonadotrophin secretion. To the authors' knowledge, the maternal-fetal transfer of $\mathrm{GnRH}$ antibodies has not been tested in any species. In this study, the hypothesis that maternally administered antibodies to GnRH would cross the fetal-placental barrier and suppress circulating fetal gonadotrophin concentrations was tested in sheep.

\section{Materials and Methods}

Fifteen cyclic Scottish Greyface ewes (3-5 years old, 53-68 kg body weight) were treated with progestagen-impregnated vaginal pessaries (Chronogest, Intervet Laboratories, Cambridge) to synchronize cycles. After 12 days, the pessaries were withdrawn and the ewes were given an i.v. injection of 300 iu PMSG. After $51 \mathrm{~h}$, the ewes were artificially inseminated with fresh ram semen. On day 98 of gestation (term $=145$ days) the jugular vein and carotid artery of the fetuses were cannulated using the method described by Brooks and White (1990). After 3 days recovery, at day 102 of gestation, serial blood samples $(0.6-0.8 \mathrm{ml})$ were taken every $15 \mathrm{~min}$ for $6 \mathrm{~h}$ from the fetuses to determine pretreatment $\mathrm{LH}$ concentrations. Immediately after the serial sampling, a GnRH challenge (100 ng i.v. bolus injection) was given to the fetuses and blood samples were taken $15,30,45,60,90$ and $120 \mathrm{~min}$ after challenge.

On day 103 of gestation, indwelling jugular catheters were inserted into the ewes and $4 \mathrm{~h}$ later, six ewes were given an i.v. infusion of $250 \mathrm{ml}$ ovine antiserum to BSA and nine ewes were infused with $250 \mathrm{ml}$ ovine antiserum to $\mathrm{GnRH}$. All infusates were administered over $1 \mathrm{~h}$.

On day 104 of gestation, serial blood samples $(0.6-0.8 \mathrm{ml})$ were taken every $15 \mathrm{~min}$ for $6 \mathrm{~h}$ from the fetuses for $\mathrm{LH}$ analysis. Immediately after the serial sampling, a $\mathrm{GnRH}$ challenge (100 ng i.v.) was given to the fetuses and blood samples taken 15, 30, 45, 60, 90 and 120 min after challenge.

Daily maternal and fetal blood samples, I day before and for 11 days after infusion, were taken for FSH and GnRH antibody titre analysis. Of the nine cannulated fetuses whose mothers were given the antiserum to $\mathrm{GnRH}$, four were male and five were female. Of the six cannulated fetuses whose mothers were given the antiserum to BSA, three were male and three were female.

\section{Hormone assays}

Plasma LH and FSH were measured in duplicate by doubleantibody radioimmunoassay (McNeilly et al., 1976; Martensz et al., 1976). The limit of detection of the LH assays was $0.29 \pm 0.07 \mathrm{ng} \mathrm{ml}^{-1}$ (mean \pm SEM). The intra-assay coefficient of variation was estimated in each LH assay using six replicates of three control samples containing $0.87(7.3 \pm 4.3 \%), 1.47$ $(8.9 \pm 3.6 \%)$ and $7.85(7.4 \pm 2.1 \%) \mathrm{ng} \mathrm{ml}{ }^{-1}$. The interassay coefficients of variation were $7.6 \%, 12.4 \%$ and $11.2 \%$, respectively, and the effect that this would have had on the detection of $\mathrm{LH}$ pulses was avoided by assaying all samples from one animal in the same run. The limit of detection of the FSH assays was $0.47 \pm 0.11 \mathrm{ng} \mathrm{ml}^{-1}$ (mean \pm SEM). The intra-assay

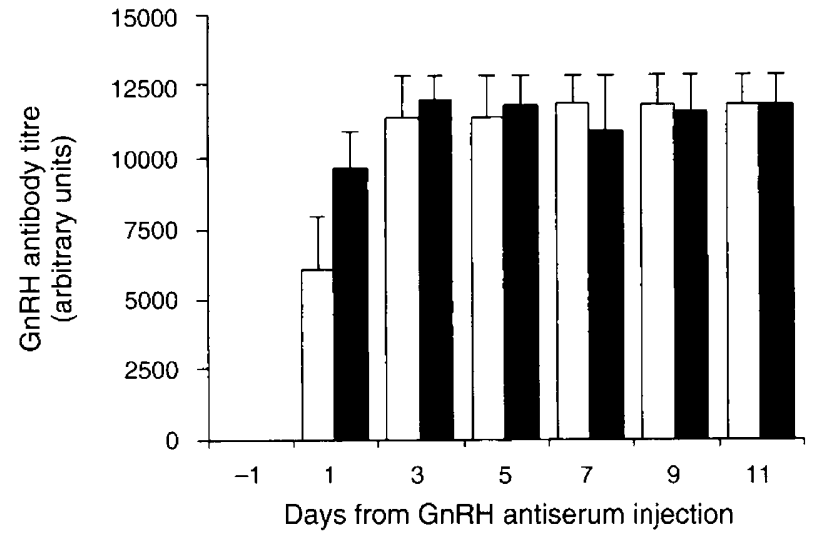

Fig. 1. Maternal $(\square, n=9)$ and combined male and female fetal ( $\square$, $n=9) \mathrm{GnRH}$ antibody titres after maternal passive immunization against GnRH in sheep. Values are means \pm sEM.

coefficient of variation was estimated in each FSH assay using six replicates of three control samples containing 0.26 $(5.9 \pm 3.4 \%), 0.47(4.2 \pm 1.2 \%)$ and $2.11(6.3 \pm 1.9 \%) \mathrm{ng} \mathrm{ml}^{-1}$. The interassay coefficients of variation were $3.1 \%, 7.4 \%$ and $6.2 \%$, respectively. Estimation of $\mathrm{GnRH}$ antibody titre was performed as described by Clarke et al. (1978) and was defined as the dilution of plasma binding $33 \%$ of a constant amount of ${ }^{125}$ I-labelled GnRH.

\section{Antiserum}

The GnRH antiserum used to treat the ewes was a pool obtained from various blood samples taken during the nonbreeding season from Ewe 4 immunized against GnRH conjugated to BSA (Fraser et al., 1981). Specificity was directed towards the C-terminal end of GnRH, which results in no significant crossreaction when tested against a variety of peptides including TRH, somatostatin, I- 6 fragment of GnRH and 3-9 fragment of GnRH (Lincoln and Fraser, 1979; Ellis et al., 1983). This antiserum was used subsequently for radioimmunoassay detection of GnRH. Control antiserum was obtained from various blood samples taken during the non-breeding season from a ewe immunized against BSA.

\section{Statistical analysis}

One-way analysis of variance was used for comparisons between treatments with no time component. Data containing a time component were tested for time and treatment effects by repeated measures analysis of variance.

\section{Results}

\section{GnRH antibody titres}

On the first day after maternal antiserum injection, GnRH antibody titres ranged from approximately 1:6000 in fetal plasma to 1:10 000 in maternal plasma (Fig. 1). By 3 days after maternal antiserum injection, both maternal and fetal plasma $\mathrm{GnRH}$ antibody titres had increased to approximately 

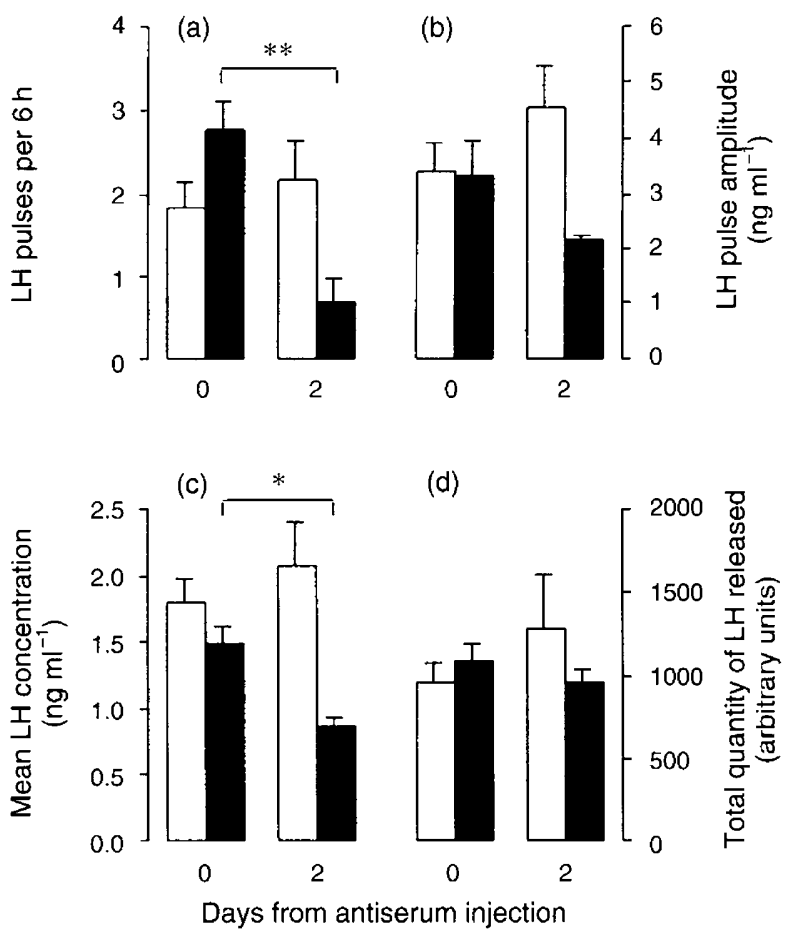

Fig. 2. Effect of maternal passive immunization against $\mathrm{GnRH}$ $n=9$ ) or BSA ( $\square, n=6$ ) on combined male and female fetal (a) $\mathrm{LH}$ pulse frequency, (b) LH pulse amplitude, (c) mean LH concentrations, and (d) LH response to a $100 \mathrm{ng}$ challenge (i.v.) of $\mathrm{GnRH}$ in sheep. Values are means \pm SEM. Significantly different: $* P<0.05$; $* * p<0.005$.

1:12000, and remained high until day 11. There was no difference between fetal and maternal GnRH antibody titres throughout the experiment. There was also no difference in the fetal GnRH antibody titres when the results were divided into male and female groups (data not shown).

\section{LH concentrations}

There were no differences between the sexes in any of the measured parameters of LH secretion and so data were combined for statistical analysis. After maternal antiserum injection, LH pulse frequency in fetuses whose mothers had been given antiserum to $\mathrm{GnRH}$ had decreased by $80 \%$ compared with values on day $0(P<0.005)$, while there was no difference in the fetuses whose mothers had been given antiserum to BSA (Fig. 2a). Similarly, mean LH concentrations in the anti-GnRH fetuses decreased by $50 \%$ compared with values on day $O(P<0.05)$, while there was no difference in the anti-BSA fetuses (Fig. 2c). There was no difference by day 2 in the anti-BSA or the anti-GnRH fetuses in LH pulse amplitude (Fig. 2b) or the total amount of $\mathrm{LH}$ released in response to a $100 \mathrm{ng}$ challenge of exogenous GnRH (Fig. 2d). There was also a suppression of LH pulse amplitude in the anti-GnRH fetuses, but this effect did not reach significance (Fig. 2b).

\section{FSH concentrations}

After injection of maternal antiserum, FSH concentrations in fetuses given both the anti-BSA and anti-GnRH antibodies

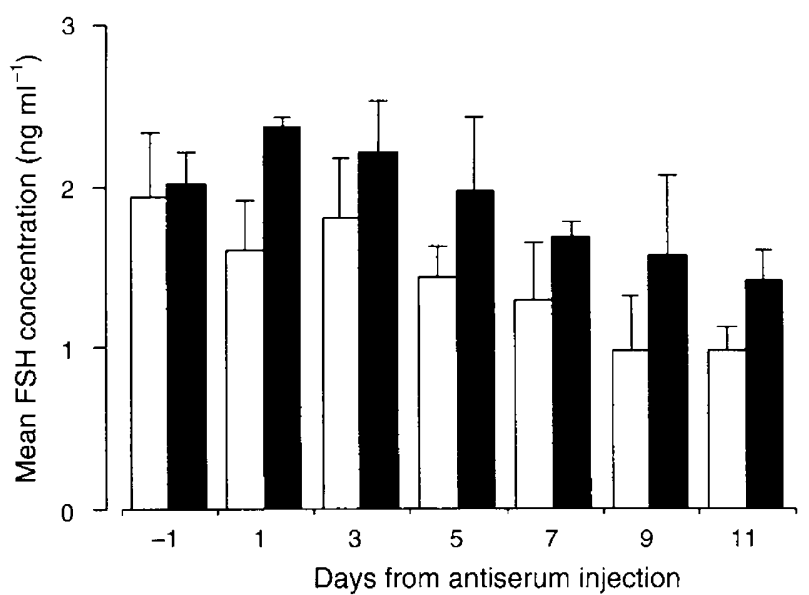

Fig. 3. Effect of maternal passive immunization against $\mathrm{GnRH}(\square$, $n=9)$ or BSA $(\mathbf{Q}, n=6$ ) on combined male and female fetal FSH concentrations in sheep. Values are means \pm SEM.

decreased, but by 11 days after injection, the concentrations in the anti-GnRH fetuses were about 30\% lower than in the fetuses given anti-BSA antibodies (Fig. 3). Repeated measures analysis indicated that after injection of the maternal antiserum there was a modest effect of treatment on mean FSH concentrations $(P=0.07)$, a significant effect of time $(P<0.05)$, but no interaction between treatment and time.

There was a sexual dimorphism in the fetal FSH concentrations in response to maternal $\mathrm{GnRH}$ antibody administration (Fig. 4). In males, FSH concentrations in both the anti-BSA and anti-GnRH fetuses declined and, by 11 days after maternal antiserum injection, the concentrations in the anti-GnRH fetuses were about 50\% lower than those in the anti-BSA fetuses. Repeated measures analysis indicated that there was a significant effect of treatment on mean FSH concentrations in males $(P=0.05)$, a modest effect of time $(P=0.09)$, but no interaction between treatment and time. In females, repeated measures analysis indicated that there was no effect of treatment or of the interaction between treatment and time on mean FSH concentrations, but a significant effect of time $(P=0.05)$. Repeated measures analysis also indicated that there was no effect of sex, time or the interaction between time and sex on FSH concentrations in the anti-BSA groups, and a highly significant effect of sex $(P<0.005)$, but not of time or the interaction between time and sex on FSH concentrations in the anti-GnRH groups.

\section{Discussion}

By cannulating maternal and fetal blood vessels in sheep, we have been able to demonstrate for the first time that maternally administered antiserum against $\mathrm{GnRH}$ crosses the fetalplacental barrier and acts on fetal gonadotrophs to suppress fetal gonadotrophin secretion. Titres of GnRH antibodies increased in maternal and fetal plasma in a similar time course and in a similar magnitude after a single maternal injection of $\mathrm{GnRH}$ antiserum. An immediate suppression of the pulsatile secretion of fetal $\mathrm{LH}$ and a gradual decrease in fetal FSH concentrations were associated with the increase in $\mathrm{GnRH}$ 

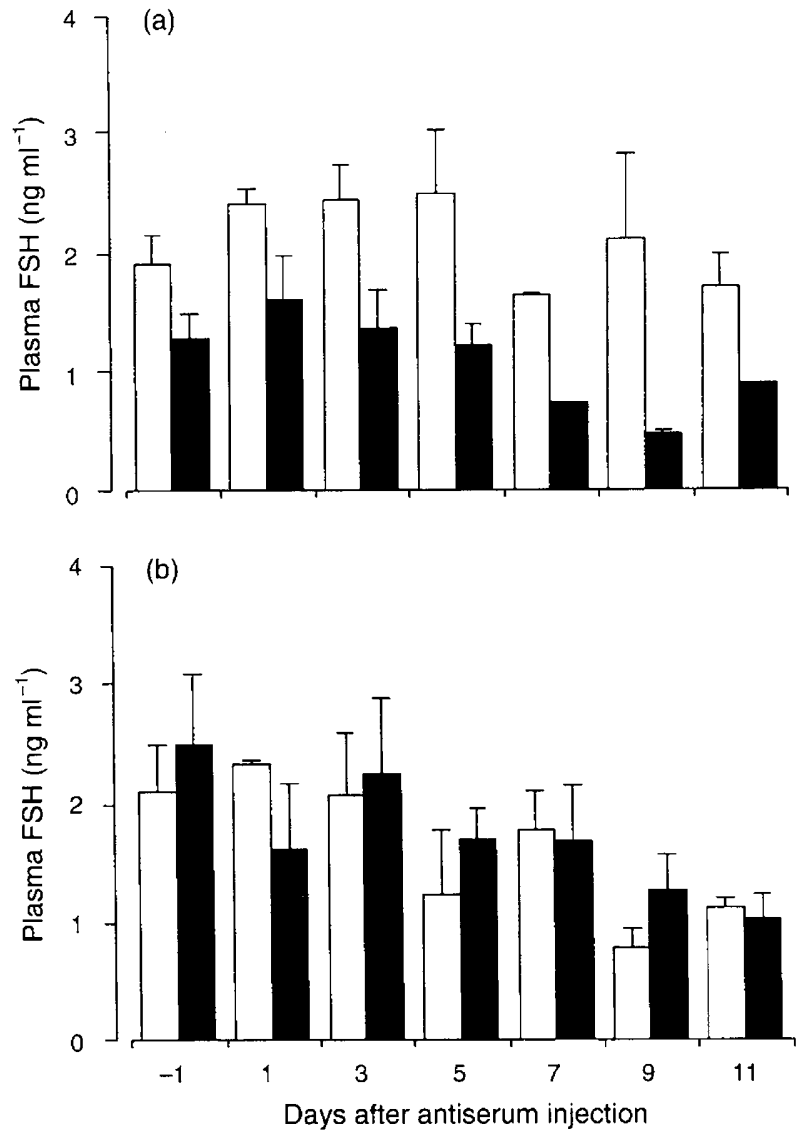

Fig. 4. Sexually dimorphic response of (a) male and (b) female fetal FSH concentrations to maternal passive immunization against GnRH (ם, male $n=4$; female $n=5$ ) or BSA $(\square$, male $n=3$; female $n=3)$ in sheep. Values are means \pm SEM.

antibody titres over the duration of the experiment. Maternal passive immunization to GnRH may provide a useful, noninvasive procedure for blocking fetal gonadotrophin secretion and, hence, allowing intricate studies into the development of the fetal reproductive axis.

The finding that the decrease in fetal FSH secretion in fetuses receiving $\mathrm{GnRH}$ antibodies was much slower than the decrease in fetal LH secretion shows that the secretion of FSH, in contrast to secretion of $\mathrm{LH}$, is not dependent on short-term changes in $\mathrm{GnRH}$ release. When physiological amounts of $\mathrm{GnRH}$ are administered in a pulsatile manner to sheep, it takes several days to modify the secretion of FSH (Lincoln, 1979). Aduit ewes actively immunized against GnRH show a clear suppression of FSH secretion, but this effect takes much longer than the suppression of LH secretion in the same experiment (Clarke et al., 1978). Sexual dimorphism in the response of fetal FSH concentrations to GnRH immunoneutralization was also apparent in the present findings. Maternal GnRH immunoneutralization suppressed male, but not female, fetal FSH secretion. It is possible that this may have resulted from an aberration caused by the small sample sizes after sexual segregation. Alternatively, it may have been due to differences in the negative feedback of the gonadal steroids, as experiments in adult ewes have shown that GnRH immunoneutralization suppresses ovarian oestradiol secretion
(McNeilly et al., 1984). Removal of the negative feedback effect of oestradiol, and perhaps inhibin, by GnRH immunoneutralization may play a compensatory role in maintaining plasma FSH concentrations at control values in the female fetuses. However, as our group have previously shown, secretion of the ovarian steroids by fetal ovaries at day 100 of gestation is undetectable (Engelhardt et al., 1995), and Mesiano et al. (1991) also reported a lack of effect of castration at days 110-115 of gestation on plasma FSH concentrations in females. Therefore, it is unlikely that differences in gonadal steroid feedback between males and females after GnRH immunoneutralization are involved in this effect. Further studies are needed to investigate the differences in the mechanistic pathways controlling FSH secretion in male and female fetuses.

The natural decrease in plasma FSH concentrations in the control fetuses over the II days of the experiment is in agreement with the decline in gonadotrophin secretion observed after mid-gestation in studies in sheep by Brooks and Thomas (1995). This decrease is related to the development of the central nervous system and the sex-steroid feedback systems, and also to an increase in placental steroid production.

The results obtained from the GnRH challenge test were equivocal. There was no difference between the anti-GnRH treated and anti-BSA control fetuses in the LH response to the $\mathrm{GnRH}$ challenge. It was expected that the $\mathrm{GnRH}$ antibodies present in the fetuses given anti-GnRH antibodies would have blocked the exogenous GnRH. The finding that the $\mathrm{LH}$ response in the treated fetuses was similar to that of the control fetuses may be due to the kinetics of the system. The bolus dose of $100 \mathrm{ng} \mathrm{GnRH}$ may have been too high for the antibodies present, thus allowing the peptide to couple with the receptors at sufficient concentrations to elicit a normal $\mathrm{LH}$ response. In addition, the LH secretory response of the pituitary gland to $\mathrm{GnRH}$ may also have been highly sensitive in the fetuses treated with anti-GnRH antibodies, as LH would have accumulated in the gonadotroph cells since synthesis and would have continued to do so throughout the treatment period when release was suppressed. A smaller dose of $\mathrm{GnRH}$ may be needed to test this system in future studies.

The success of this initial experiment suggests that this procedure should be developed for possible use in fetal studies. The effect of GnRH immunoneutralization also needs to be tested, for example, at earlier gestational ages, given that in humans the maternofetal transport system for immunoglobulins requires maturation. It has been found that immunoglobulin transfer starts during the middle of gestation and gradually increases in proportion to the gestational age (Stiehm, 1975).

In conclusion, immunoneutralization of maternal GnRH suppresses fetal LH and FSH concentrations in male sheep, and LH concentrations in female sheep. Although the lack of effect on FSH secretion in females needs to be investigated further, with larger sample sizes, this model should provide a valuable, non-invasive method to manipulate hypothalamo-pituitarygonadal function in the developing fetus. This is of particular importance during early gestation when it is not possible to intervene via current models that involve surgical manipulation.

The animals used in this study were cared for by D. Doogan, N. Anderson, J. Docherty and co-workers. This work was funded by a 
Wellcome Travelling Postdoctoral Fellowship awarded to D.W. Miller. Immunoreagents were kindly donated from the National Institute of Diabetes, Digestive and Kidney diseases (NIDDK).

\section{References}

Brooks AN and Thomas GB (1995) Ontogeny and function of the pituitarygonadal axis during fetal development in sheep Reproduction in Domestic Animals 30 158-162

Brooks AN and White A (1990) Activation of pituitary-adrenal function in fetal sheep by corticotrophin-releasing factor and arginine vasopressin Journal of Endocrinology $124 \quad 27-35$

Clarke IJ, Fraser HM and McNeilly AS (1978) Active immunization of ewes against luteinizing hormone releasing hormone and its effects on ovulation rate and gonadotrophin prolactin and ovarian steroid secretion Journal of Endocrinology $\mathbf{7 8} 39-47$

Ellis GB, Desjardins C and Fraser HM (1983) Control of pulsatile LH release in male rats Neuroendocrinology 37 177-183

Engelhardt H, Harkness LM, Thomas GB, Brooks AN, McNeilly AS and Baird DT (1995) Expression of inhibin alpha-subunit and beta-a-subunit messengerRNA and protein in the fetal sheep ovary throughout gestation Molecular and Cellular Endocrinology 107 141-147

Fraser HM and McNeilly AS (1983) Differential effects of LH-RH immunoneutralization on LH and FSH secretion in the ewe Journal of Reproduction and Fertility $69569-577$

Fraser HM, Clarke IJ and McNeilly AS (1981) Effect of oestrogen and an LH-RH agonist on the release of gonadotriphins in ovariectomized ewes deprived of LH-RH Journal of Reproduction and Fertility 62 131-140

Isreal EJ, Patel VK, Taylor SF, Marshakrothstein A and Simister N (1995) Requirement for a beta(2)-microglobulin-associated Fc receptor for aquisition of maternal IgG by fetal and neonatal mice Journal of Immunology 154 6246-6251

Jauniaux E, Jurkovic D, Gulbis B, Liesnard C, Lees C and Campbel S (1995) Materno-fetal immunoglobulin transfer and passive immunity during the first trimester of human pregnancy Human Reproduction 10 3297-3300
Jensen TK, Toppari J, Keiding N and Skakkebaek NE (1995) Do environmental estrogens contribute to the decline in male reproductive health? Clinical Chemistry 41 1896-1901

Lincoln GA (1979) Use of a pulsed infusion of LH-RH to mimic seasonally induced endocrine changes in the ram Joumal of Endocrinology $83251-260$

Lincoln GA and Fraser HM (1979) Blockade of episodic secretion of luteinizing hormone in the ram by the administration of antibodies to luteininzing hormone releasing hormone Biology of Reproduction 21 1239-1245

McNeilly AS, Fraser HM and Baird DT (1984) Effects of immunoneutralization of $\mathrm{LH}$ releasing hormone on LH, FSH and ovarian steroid secretion in the preovulatory phase of the oestrous cycle in the ewe Journal of Endocrinology $101213-219$

McNeilly JR, McNeilly AS, Walton JS and Cunningham FJ (1976) Development and application of a heterologous radioimmunoassay for ovine folliclestimulating hormone Journal of Endocrinology 70 69-79

Martensz ND, Baird DT, Scaramuzzi RJ and Van Look PFA (1976) Androstenedione and the control of luteinizing hormone in the ewe during anoestrus Journal of Endocrinology 69 227-237

Mesiano S, Hart CS, Heyer BW, Kaplan SC and Grumbach MM (1991) Hormone ontogeny in the ovine fetus 26 . A sex difference in the effect of castration on the hypothalamic-pituitary gonadotropin unit in the ovine fetus Endocrinology 129 3073-3079

Sanderson TP, Andersen AA, Miller LD, Andrews JJ, Janke BH, Larson DL and Schwartz KJ (1994) An indirect immunoflourescence test for detection of chlamydial antibodies in ovine fetal fluids Journal of Veterinary Diagnostic Investigation 6 315-320

Stiehm RE (1975) Fetal defense mechanisms American Journal of Diseases in Children 129 438-449

Thomas GB, McNeilly AS, Gibson F and Brooks AN (1994) Effects of pituitarygonadal suppression with a gonadotropin-releasing hormone agonist on fetal gonadotropin secretion, fetal gonadal development and maternal steroid-secretion in the sheep Journal of Endocrinology 141 317-324

Tuo WB, Zhu DM and Bazer FW (1996) Transfer of heterologous immunoglobulin into the uterine lumen of pigs Journal of Reproductive Immunology 32 145-155 